\title{
Effect of Molybdate on Phosphating of Nd-Fe-B Magnets for Corrosion Protection
}

\author{
Adonis Marcelo Saliba-Silva*, Mara Cristina Lopes de Oliveira, Isolda Costa* \\ Instituto de Pesquisas Energéticas e Nucleares, IPEN/CNEN-SP \\ Centro de Ciência e Tecnologia de Materiais \\ Cx. Postal 11049, Pinheiros, 05422-970 São Paulo, Brazil
}

Received: November 23, 2003; Revised: February 16, 2005

\begin{abstract}
$\mathrm{Nd}-\mathrm{Fe}-\mathrm{B}$ magnets are highly susceptible to corrosion and need protection against environment attack. The use of organic coatings is one of the main methods of corrosion protection of these materials. Data related to the effect of conversion coatings, such as phosphating, on corrosion performance of these magnets is still scarce. Studies about the effect of phosphating on the corrosion resistance of a commercial Nd-Fe-B sintered magnet indicated that it increases the corrosion resistance of these magnets, compared to non-phosphated magnets. In this study, the solution chemistry of a phosphating bath was altered with the addition of molybdate and its effect on the corrosion resistance of magnets investigated. Sintered magnet specimens were phosphated in solutions of $10 \mathrm{~g} / \mathrm{L}$ $\mathrm{NaH}_{2} \mathrm{PO}_{4}(\mathrm{pH} 3.8)$, either with or without molybdate $\left[10^{-3} \mathrm{M} \mathrm{MoO}_{4}^{2-}\right]$, to improve their corrosion resistance. The effect of phosphating time was also evaluated, and specimens were phosphated for 4 and 18 hours. To evaluate the corrosion performance of phosphated and unphosphated specimens, a corrosion test based on monitoring hydrogen evolution on the surface of the magnets was used. This technique revealed that the addition of molybdate to the phosphating solution improved the corrosion resistance of the magnets phosphated by immersion for short periods but had no beneficial effect if phosphated by immersion for longer periods.
\end{abstract}

Keywords: corrosion, $\mathrm{Nd}-\mathrm{Fe}$-B magnets, phosphating, molybdate

\section{Introduction}

$\mathrm{Nd}-\mathrm{Fe}-\mathrm{B}$ magnets produced by powder metallurgy have a wide range of applications, from computer disk drives, many important parts of fine electro-electronic industry to large industrial machines. However, these magnets have low corrosion resistance and their surfaces need protection. The low corrosion resistance is due partially to its complex microstructure, with two electrochemically different primary phases ( $\varphi$-phase and Nd-rich), that leads to galvanic corrosion. Moreover, magnets produced by powder metallurgy (PM) techniques are porous, which decreases further its corrosion resistance.

Corrosion control methods are necessary to make it viable to use $\mathrm{Nd}-\mathrm{Fe}-\mathrm{B}$ magnets as an engineering material. One of the most widely used corrosion control method, for this kind of magnet, is coating the magnet, mainly with organic coatings. Unfortunately, organic coatings are not defect free. Therefore, pre-treated surfaces are used, either to improve coating adhesion or to improve the corrosion resistance at the defects in the coating.

Phosphating as a pre-coating surface treatment is the object of this study. Previous studies carried out in our laboratory ${ }^{1-6}$ indicated that phosphating in a solution of $\mathrm{NaH}_{2} \mathrm{PO}_{4}$ increased the corrosion resistance of these magnets as compared to unphosphated ones. The complex microstructure of sintered Nd-Fe-B magnets, with phases exhibiting different electrochemical behavior, and pores, affect phosphating, impeding thus the formation of a continuous conversion layer.

Bala et al. ${ }^{7}$ carried out experiments with individual phases of $\mathrm{Nd}-\mathrm{Fe}-\mathrm{B}$ magnets that were synthetically prepared, and showed that the corrosion potential of the individual phases was significantly different and dependent on the solution $\mathrm{pH}$. The $\mathrm{Nd}$-rich phase rapidly dissolved into $\mathrm{Nd}^{3+}$ in solutions with $\mathrm{pH}$ less than 3.5.

Saliba-Silva et al. ${ }^{2-5}$ reported increased corrosion resistance of $\mathrm{Nd}-\mathrm{Fe}-\mathrm{B}$ magnets phosphated in a solution with $\mathrm{pH}$ of approxi- mately 3.8. According to literature ${ }^{8}$, in solutions with $\mathrm{pH}$ between 3.5 and 5, a Nd hydroxide tends to form on the surface, and this probably impairs the formation of a stable phosphate layer on the surface of the magnet. Previous results 2 have shown that in very low $\mathrm{pH}(\mathrm{pH} \leq 2)$ solutions, no protective layer formed on Nd-Fe-B magnet.

The use of oxidants in phosphating solutions is normal practice, as they accelerate the first stage of phosphating (acid attack), hindering the $\mathrm{H}_{2}$ evolution reaction and permitting access of large molecules, such as $\mathrm{PO}_{4}^{3-}$, to the metallic surface, to form a primer layer of phosphate.

There are several ways of accelerating commercial phosphating of ferrous materials, for instance, by using nitrates and chlorates. These substances are however very active and promote severe corrosion of Nd-Fe-B magnets, mainly of the Nd-rich phase ${ }^{9}$. Lorin ${ }^{10}$ suggested a variety of accelerators, even molybdates, which are not as corrosive as nitrates and chlorates. According to Gentil ${ }^{11}$, the molybdate anion $\left(\mathrm{MoO}_{4}{ }^{2-}\right)$ should be an adequate inhibitor for post-phosphating treatment, to seal the phosphate layer. Studies with molybdates have shown that they are good inhibitors for ferrous alloys ${ }^{12,13}$. Normally in commercial practice, molybdates are not used as phosphating accelerators, but are being considered as a replacement for chromatizing.

In this work, the corrosion resistance of Nd-Fe-B magnet specimens, either unphosphated or phosphated in $\mathrm{NaH}_{2} \mathrm{PO}_{4}(\mathrm{pH} 3.8)$ solutions, with or without molybdate $\left[10^{-3} \mathrm{M} \mathrm{MoO}_{4}^{2-}\right]$, for 4 hours and 18 hours, has been evaluated by a corrosion test based on monitoring the hydrogen evolution reaction on the magnet's surface. This method consists of monitoring the stages of the hydrogen evolution reaction on the magnet's surface, that is, nucleation, growth and $\mathrm{H}_{2}$ bubble release from unphosphated or phosphated magnets immersed in acid solution, at increasing times, and fitting the results to Avrami's equation $^{14}$.

*e-mail: saliba@ipen.br, icosta@ipen.br 


\section{Experimental Procedure}

\subsection{Material}

A commercial sintered Nd-Fe-B magnet produced by Crucible - U.S.A., (composition given elsewhere ${ }^{3}$ ) was used in this investigation.

\subsection{Specimen preparation}

Nd-Fe-B magnets had one of their surfaces, with an area of approximately $130 \mathrm{~mm}^{2}$ for exposure to the test solution, prepared by grinding with silicon carbide paper up to $\# 1000$, followed by degreasing with acetone in an ultrasonic bath, and drying in a hot air stream. The remaining areas were coated with varnish.

\subsection{Phosphating}

Phosphating was carried out by immersion of the magnet specimens for periods of 4 hours or 18 hours, in either one of two solutions: i) solution A: a solution made with $10 \mathrm{~g} / \mathrm{L} \mathrm{NaH}_{2} \mathrm{PO}_{4}$ and acidified with $\mathrm{H}_{3} \mathrm{PO}_{4}$ to $\mathrm{pH} 3.8$; and ii) solution $\mathrm{B}$ : $10 \mathrm{~g} / \mathrm{L} \mathrm{NaH} \mathrm{PO}_{4}$ solution with addition of $1 \mathrm{mM}$ of ammonium molybdate.

\subsection{Corrosion testing}

Corrosion testing of Nd-Fe-B magnets, either phosphated or unphosphated, was carried out by immersing the magnet specimens in an acid solution (diluted $\mathrm{HCl}$ with $\mathrm{pH}$ adjusted to 2.0) and monitoring the $\mathrm{H}_{2}$ evolution reaction on the surface of the magnet. The nucleation, growth and release of $\mathrm{H}_{2}$ bubbles from the magnet's surface, either phosphated or unphosphated, were followed with time and captured on film. The method adopted consists of fitting the surface ratio covered with $\mathrm{H}_{2}$ bubbles at increasing times of immersion, to Avrami's equation:

$$
X=1-\exp \left(-K \cdot t^{\mathrm{n}}\right)
$$

where: $\mathrm{X}$ is the surface ratio covered with $\mathrm{H}_{2}$ bubbles, due to the corrosion in the acid test solution; $\mathrm{K}$ is a constant related to the system activation energy; $\mathrm{t}$ is the reaction time; and $\mathrm{n}$ is a parameter, characteristic of the system, that is lower than 1 for liquid/gas interfaces ${ }^{15}$. Saliba-Silva ${ }^{3}$ in a previous work, found that $\mathrm{n}=0.86$ gave results that fitted well for Nd-Fe-B sintered magnets under similar conditions.

\section{Results and Discussion}

The magnet surfaces, unphosphated or phosphated, at increasing times of immersion in the test solution, are shown in Figure 1. The figure clearly shows the evolution of $\mathrm{H}_{2}$ bubbles on the magnet surfaces at increasing times of immersion in dilute $\mathrm{HCl}$ solution $(\mathrm{pH} 2.0)$.

There are few bubbles on the unphosphated magnet surface immediately after immersion. After 15 seconds, $\mathrm{H}_{2}$ bubbles completely covered the surface of the unphosphated magnet, suggesting fast kinetics of nucleation and growth on the surface. The phosphated magnets showed different behavior depending on phosphating conditions. The specimen phosphated in solution A for 4 hours showed bubbles on its surfaces after only 15 seconds of immersion and fast growth kinetics from that time onwards. The magnets phosphated in solution A for 18 hours demonstrated the best corrosion performance among all the specimens that were tested. On these specimens, only a few bubbles nucleated on its surface after 120 seconds of immersion in the acid solution. Phosphating in molybdate containing solution (solution B), resulted in improved corrosion resistance of the magnet surfaces compared to unphosphated specimens, but the increase in phosphating time in this solution was not as effective as that in the solution without molybdate. A comparison of the magnet surfaces phosphated for 18 hours in solutions A and B, indicates that molybdate has no beneficial effect on phosphating of Nd-Fe-B magnets for long periods.

The ratio of the magnet's surface with $\mathrm{H}_{2}$ bubbles, unphosphated or phosphated, as a function of immersion time was fitted to Avrami's equation, and the results are shown in Figure 2. The curves in Figure 2 consist of three distinct regions. There is an initial period, when no bubbles or very few $\mathrm{H}_{2}$ bubbles are seen on the magnet's surface (nucleation period), an intermediate region where the surface ratio covered with $\mathrm{H}_{2}$ bubbles increases rapidly with immersion time (growth period). A final region appears where there is a competition between $\mathrm{H}_{2}$ bubble growth and its release from the surface, resulting in reduced variation of the surface ratio with $\mathrm{H}_{2}$ bubbles, with time (gas evolution period).

Figure 2 shows a distinct behavior for the various types of surfaces that were tested. A very short nucleation period is followed by a short growth period of very fast kinetics, and then a prompt gas evolution period for the unphosphated magnet. Longer nucleation periods for all phosphated magnets, signaling the formation of a protective conversion layer on their surfaces. The kinetics of the growth period was dependent on the phosphating conditions. For the magnets phosphated in the molybdate containing solution (solution B), similar kinetics was obtained for the two times of phosphating ( 4 hours and 18 hours). The increase in phosphating time in this solution had a significant effect only on the nucleation period, causing its increase, but no substantial effect on either the growth or gas evolution period.

Based on previous results obtained by Saliba-Silva ${ }^{3}$, who found that $\mathrm{n}=0.86$ produced good fitting between experimental results for $\mathrm{Nd}-\mathrm{Fe}-\mathrm{B}$ sintered magnets and Avrami's equation, under conditions similar to those used in this study, $\mathrm{n}=0.86$ was adopted in Avrami's equation, to obtain the following equation:

$\ln (1-\mathrm{X})=-\mathrm{K} \cdot \mathrm{t}^{0.86}$

The results presented in Figure 2 were adjusted to Equation 2, and good fitting $\left(\mathrm{R}^{2}>0.99\right)$ was attained, obtaining linear plots from which the $\mathrm{K}$ values, shown in Table 1 , were estimated. The $\mathrm{K}$ values are related to the kinetics of the growth period. Table 1 also indicates the nucleation period, estimated as the time during which the surface ratio with $\mathrm{H}_{2}$ bubbles was approximately zero.

As shown in Table 1, phosphating in the $\mathrm{NaH}_{2} \mathrm{PO}_{4}$ solution without molybdate causes an increase in the corrosion resistance of the magnet with increase in phosphating time. This reflects a strong effect of phosphating time on the development of the conversion layer. Phosphating for 18 hours in this solution resulted in an extremely well protected surface, which significantly extended the nucleation period, to approximately 20 times, compared to the unphosphated surface. It also caused a substantial decrease in the kinetics of the growth period.

A comparison of the results of magnets phosphated in solutions A and $\mathrm{B}$, show that the effect of molybdate for short phosphating times was mainly on the kinetics of the growth period. For longer phosphating times (18 hours), molybdate had no beneficial effect on the corrosion resistance of the magnet's surface compared to that phosphated in solution A. In fact, comparison of magnets phosphated for 18 hours in both solutions indicates that the molybdate had a detrimental effect on the corrosion resistance. One of the possible reasons for this behavior is that a surface oxide is essential for corrosion inhibition of ferrous materials by the molybdate ions ${ }^{16}$. According to literature ${ }^{17}$, an oxide layer can exist on the surface up to the bulk $\mathrm{pH}$ of (as low as) 4. As the $\mathrm{pH}$ of the solution used for phosphating was 3.8 , it is possible that the $\mathrm{MoO}_{4}{ }^{2-}$ ions could not act as a corrosion inhibitor. Moreover, phosphate and molybdate ions must compete for the surface, and 


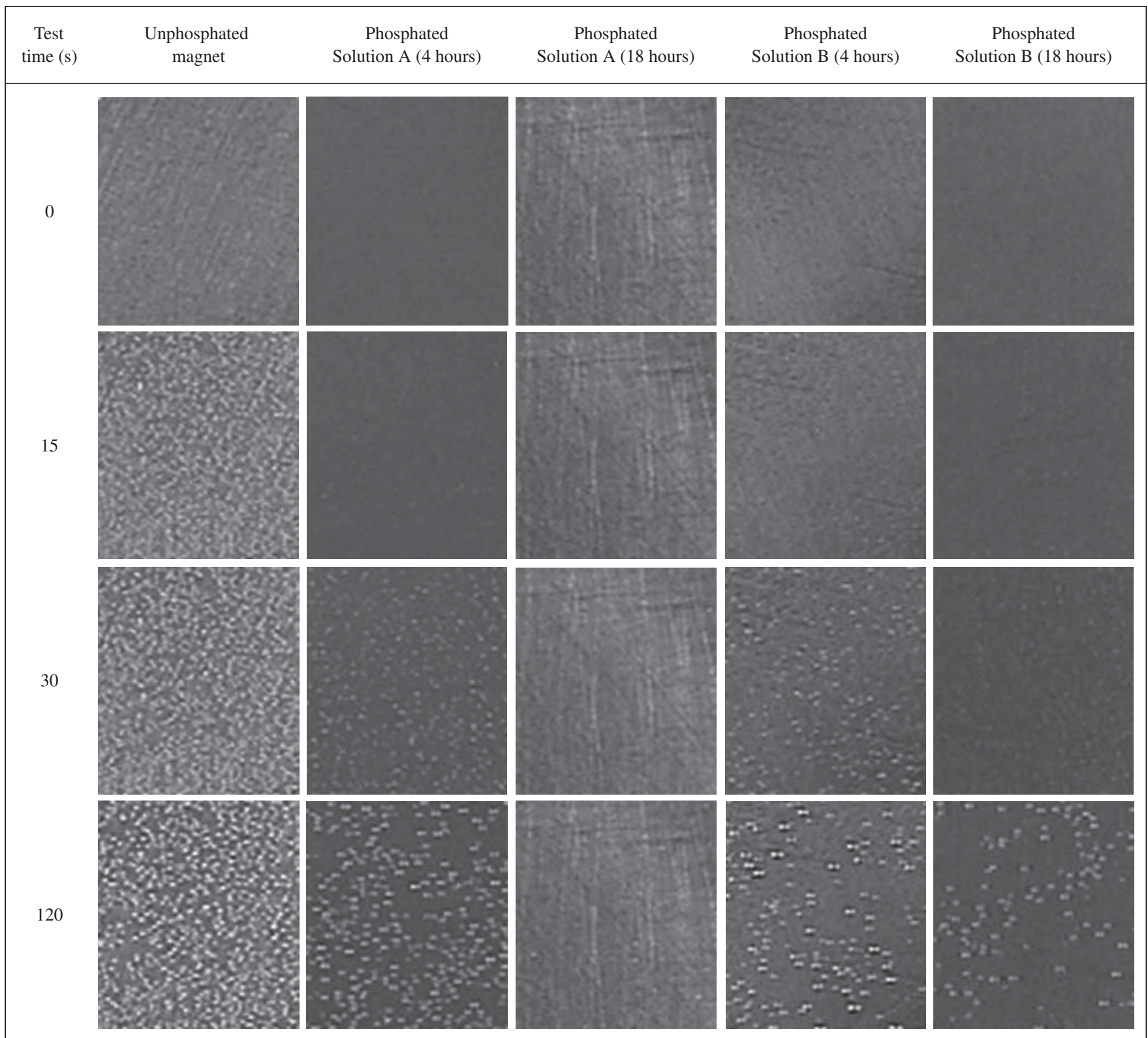

Figure 1. Surface of sintered Nd-Fe-B magnets, unphosphated or phosphated in solutions A or B, for periods of 4 hours or 18 hours, at increasing times of immersion in acid solution (dilute $\mathrm{HCl}$ solution with $\mathrm{pH}$ adjusted to 2). The nucleation, growth and $\mathrm{H}_{2}$ bubble release from the magnet surfaces, is easily seen. Photographs [magnitude: $10 \mathrm{x}$ ] were obtained from time-controlled film recording.

Table 1. K values and nucleation period obtained from experimental results fitted to Avrami's equation for the various types of magnet surfaces that were tested.

\begin{tabular}{lcc}
\hline \multicolumn{1}{c}{ Magnets } & $-\mathrm{K}$ & Nucleation period (s) \\
\hline Unphosphated & 1.01 & 7 \\
Phosphated Sol. A (4 h) & 0.75 & 20 \\
Phosphated Sol. A (18 h) & 0.23 & 148 \\
Phosphated Sol. B (4 h) & 0.35 & 14 \\
Phosphated Sol. B (18 h) & 0.29 & 19 \\
\hline
\end{tabular}

the eventual adsorption of molybdate on some metallic sites makes the surface negatively charged, repelling the charged $\mathrm{PO}_{4}{ }^{2-}$ ions, and consequently impairing phosphating of the surface.

Nevertheless, for specimens phosphated for 4 hours, the molybdate seems to have some beneficial effect on the corrosion resistance of the magnet, as indicated by a reduction in the kinetics of the growth period. Taking into account this observation, some technological improvements are necessary to add molybdate to the phosphating solution, as long periods of phosphating are used. The effect of a two-stage process, with phosphating first in solutions without molybdate followed by immersion in a molybdate-based solution, is under investigation.

\section{Conclusions}

Molybdate addition $\left(10^{-3} \mathrm{M}\right)$ to a phosphating solution $10 \mathrm{~g} / \mathrm{L}$ $\mathrm{NaH}_{2} \mathrm{PO}_{4}(\mathrm{pH} 3.8$ ) had a marginally positive effect on the corrosion resistance of Nd-Fe-B magnets phosphated for 4 hours compared to a similar phosphating solution, and had a detrimental effect when a longer phosphating period (18 hours) was used.

A new method of evaluating the corrosion resistance of conversion coating layers, based on fitting the experimental results of $\mathrm{H}_{2}$ 
Relative surface corrosion of treated and untreated NdF e B magnets comparasion between phosphating solution with and without $\mathrm{MoO}_{4}$ addition

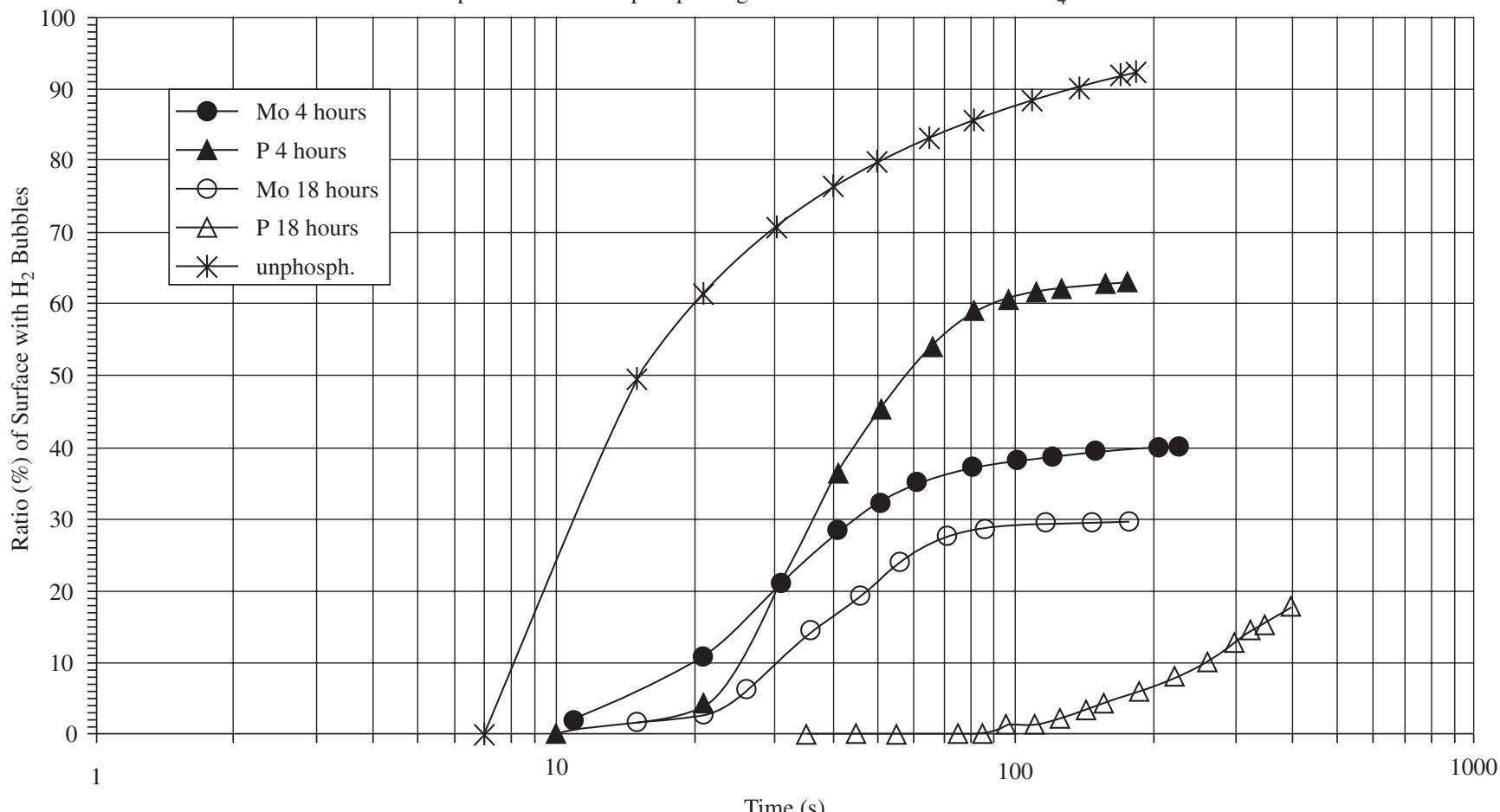

Figure 2. Nd-Fe-B magnet's surface ratio with $\mathrm{H}_{2}$ bubbles with time of immersion in dilute $\mathrm{HCl}$ solution (pH adjusted to 2). Magnets were tested either unphosphated or phosphated in solution $\mathrm{A}\left(10 \mathrm{~g} / \mathrm{L} \mathrm{NaH}_{2} \mathrm{PO}_{4}\right)$ or solution $\mathrm{B}\left(10 \mathrm{~g} / \mathrm{L} \mathrm{NaH} \mathrm{PO}_{4}+1 \mathrm{mM} \mathrm{MoO}_{4}^{2-}\right)$ for 4 hours or 18 hours.

evolution on the treated surface to Avrami's equation is proposed. This method showed good results for the sintered Nd-Fe-B magnet, either phosphated or unphosphated, that were corrosion tested by immersion in an acid solution $(\mathrm{pH}=2)$.

\section{References}

1. Costa I, Sayeg IJ, Faria RN. The corrosion protection of RE-iron-boron magnets by a phosphate treatment. IEEE Transactions on Magnetics. 1997; 33(5):3907-3909.

2. Saliba-Silva AM. Development of a phosphating process for corrosion protection of NdFeB magnets. São Paulo: Universidade de São Paulo/ IPEN; 2001, 149 p. In Portuguese.

3. Saliba-Silva AM, Costa I. Corrosion protection of a commercial NdFeB magnet by phosphating. Key Engineering Materials. 2001; 189-191:363368.

4. Saliba-Silva AM, de Melo HG, Baker MA, Brown AM, Costa I. Characterization of sintered $\mathrm{NdFeB}$ magnets after phosphating in alkaline and acidic environments. Materials Science Forum. 2003; 416-418:54-59.

5. Saliba-Silva AM, Faria RN, de Melo HG, Costa I. Improving the corrosion resistance of $\mathrm{NdFeB}$ magnets: na electrochemical and surface analytical study. Surface and Coatings Technology. 2004; 185(2-3):321-328.

6. Saliba-Silva AM, Baker MA, de Melo, HG, Costa I, Brebbia, Editor Corrosion protection of sintered $\mathrm{NdFeB}$ magnets by phosphating. Surface Treatment V, Series: Computational and Experimental Methods. 2001; p. 65.

7. Bala H, Pawlowska G, Szymura S, Rabinovich YM. Electrochemical corrosion characterisation of intermetallic phases occurring in Nd-Fe-B type magnets. British Corrosion Journal. 1998; 33(1):37-41.
8. Rupp B, Resnik A, Shaltiel D, Rogl P. Phase-Relations and Hydrogen Absorption of Neodymium Iron (Boron) Alloys. Journal of Materials Science. 1988; 23(6):2133-2141.

9. Tokuhara K, Hirosawa S. Corrosion-Resistance of Nd-Fe-B Sintered Magnets. Journal of Applied Physics. 1991; 69(8):5521-5523.

10. Lorin G. Phosphating of Metals - Constituition. Middlelsex, England: Finishing Publications Ltd; 1974.

11. Gentil V. Corrosion, $3^{\text {rd }}$ Edition. Rio de Janeiro, Brazil: LTC Editora; 1996. p. 213. In Portuguese.

12. Magalhães AAO, Margarit ICP, Mattos OR. Study of Molybdate Conversion Coatings on Zinc Surfaces. In: Proceedings of $7^{\mathrm{th}}$ International Symposium on Electrochemical Methods in Corrosion Research. 28 May - 01 Jun. 2000; Budapest, Hungary. Budapest: International Society of Electrochemistry; 2000. Paper 100.

13. Martini EMA, Azambuja DS, Piatnicki CS, Muller IL. A comparative study of the inhibiting effect of molibdate, tungstate and vanadate on iron corrosion. In: Proceedings of $20^{\text {th }}$ Brazilian Corrosion Congress. Fortaleza, Brazil, 12-15 Sept. 2000. In Portuguese. Fortaleza: Associação Brasileira de Corrosão; 2000. Paper R071, [CD-ROM].

14. Avrami M. Kinetics of Phase Change I. Journal of Chemical Physics. 1939; 7:1103.

15. Smith GW. A method for determination of Avrami parameters directly from isothermal calorimetry data. Thermochimica Acta. 1997; 291(1-2):59-64.

16. Farr JPG, Seeney AM, Bentley AJ, Earwaker LG. A technique for the insitu elemental analysis of electrode surfaces. Surface Technology. 1984; 23(1):99-103

17. Uhlig HH, Corrosion and Corrosion Control. London: John Wiley and Sons. 1967; p.85. 